\title{
BIM-based Operational Information Requirements for Asset Owners
}

\author{
Mustapha Munir, Arto Kiviniemi, Stephen W. Jones, Stephen Finnegan
}

\begin{abstract}
It is widely recognised in the Architecture, Engineering and Construction (AEC) industry that asset owners do not really understand their information needs for effective BIMbased Asset Management (AM). Hence, they may be unable to develop their operational information requirements to request the right data from the design and construction phases. This paper investigates the operational information requirements of three asset owners through a comparative study. A qualitative multi-case study approach was used to collect and analyse the operational information requirements of three asset owners. A qualitative content analysis was also utilised to identify key asset information requirements and categories. The study revealed that operational information requirements are strongly related to business needs and that it is not possible to develop a rigid list of requirements for asset owners, but rather some templates to help them define their data requirements. Of a total of 172 analysed information requirements, only 7 requirements were common in all cases and 16 were common in 2 cases, which represents $4 \%$ and $9 \%$ of the total. The research addressed a significant research gap regarding the development of operational information requirements for asset owners. Moreover, the paper provides templates to help guide asset owners when defining their data requirements for asset operations in order to derive BIM business value.
\end{abstract}

KEYWORDS: BIM, AM, FM, Operational Information Requirements, Business Value 


\section{Introduction}

Building Information Modelling (BIM) can offer significant support to asset owners in the lifecycle management of their information assets. This can be achieved through enhanced data management, data usability, real-time data access, visualisation, and efficiency in maintenance management (Becerik-Gerber, Jazizadeh, Li, \& Calis, 2012; Cavka, Staub-French, \& Poirier, 2017). Increasingly, asset owners are developing guidelines and deliverables for BIM-based processes to address the challenges associated with poor information fidelity (Kensek, 2015; Cavka, Staub-French, \& Poirier, 2018). This is due to the fact that asset managers rarely get the data that they need because such information is usually embedded with significant amounts of unusable parameters (Brous, Herder, \& Janssen, 2016). Moreover, operational personnel commonly struggle to articulate their BIM-based information requirements, and when they are asked to specify the requisite data that are critical for asset operations, they ask for everything (Hoyer, Maclnnis, \& Pieters, 2013). As a consequence, operational personnel are overloaded with information, and are unable to filter the essential data needed to perform Asset Management (AM) tasks and derive BIM business value in asset operations. The inability of asset managers in the Architecture, Engineering and Construction (AEC) industry to articulate their operational information requirements from the design and construction phases is one of the biggest barriers to BIM implementation in asset operations (Becerik-Gerber et al., 2012). Hence, there is a need to research the ways in which to identify operational information requirements for BIM-based processes.

Understanding the information needs of asset managers can be difficult, especially when trying to capture the feelings and perceptions of users for an intangible resource within owner-operator organisations (Irani, 2010). This is because people rarely focus on their needs and values, and as a result, experience difficulties in their articulation (Hoyer et al., 2013). Similarly, Cavka et al. (2017) highlighted the lack of awareness on how to request information 
to support BIM-based processes in asset operations. Furthermore, there are no comprehensive details to support the execution of Employer Information Requirement (EIR) activities; this is due to an insufficient understanding of the requirement specifications, processes and competencies amongst stakeholders in the operations and use phase for real value to be realised (Ashworth, Tucker, \& Druhmann, 2017; Jupp \& Awad, 2017). It is therefore essential for organisations to define operational information requirements, which can be used to request and identify the right information based on well-defined criteria that are aligned with business needs and business value realisation management (Love, Matthews, Simpson, Hill, \& Olatunji, 2014; Brous et al., 2016). In order to realise the value of information, data users must ultimately understand its nature and determine its suitability for intended use in the organisational business processes (Dawes, 2010). As such, there is a need to develop industry standards that define processes, data protocols, and the relationship between data and business needs in order to derive value from the BIM-based processes in AM (Love et al., 2014; Jupp \& Awad, 2017).

The introduction of BIM and especially Construction Operations Building Information Exchange (COBie), aimed to provide asset and facility managers with the necessary information to manage and operate a facility. However, the AEC industry is confronted with the challenges of identifying essential datasets for asset operations, which is due to the multitudinous data dimensions provided by COBie. It is worth noting that the availability of more data does not automatically translate to better information or more informed decisions. Indeed, it is estimated that more than $70 \%$ of the data generated in owner-operator organisations are never used (Lin, Gao, \& Koronios, 2008). Moreover, asset managers claim to be drowning in data but starving for information. Hence, there is a need to study and identify what asset managers actually need to do their work in order to derive value from BIM-based AM data. 
This study focused on three issues: a lack of clear understanding of the information needs in AM business processes; an analysis of the most frequently defined operational information requirements; and how these requirements are defined and structured in the operations and use phase. Therefore, this study investigated the operational information requirements of three asset owners through a comparative study in order to identify the strategies, tools and techniques for requirement development, and the most commonly defined information requirements by asset owners.

\section{Literature Review}

\section{Business Value of Operational Information Requirements for BIM-Based Processes}

For effective AM processes, asset managers need data that are reliable, accurate, consistent and timely in order to execute their tasks. A poor understanding of information requirements amongst managers in terms of the level of detail, nature of data, and format required has affected the momentum of BIM adoption in asset operations and hindered the subsequent value realisation by asset owners (Parsanezhad \& Dimyadi, 2014). Certainly, there is increasing evidence of BIM business value in AM (Cavka et al., 2017). Despite this, AM business needs in relation to operational information requirements have not been extensively studied (Becerik-Gerber et al., 2012; Korpela, Miettinen, Salmikivi, \& Ihalainen, 2015). In an effort to identify these requirements, Becerik-Gerber et al. (2012) highlighted areas of BIM implementation in asset operations that could create business value for asset owners by defining their business-level data requirements. Similarly, Cavka et al. (2017) developed an iterative approach to identify information requirements through linkages with business needs. This aims to formalise the process so that asset owners can derive value from BIM-based asset data. Also, there have been efforts to develop and test an EIR template, including a guidance document 
designed to meet the organisational business-level needs of BIM-based processes (Ashworth \& Tucker, 2017a; Ashworth et al., 2017b). As a criterion, Brous et al. (2016) suggested that data governance programmes should aim to demonstrate business value. The resolution of the problem is highly dependent on how asset owners articulate their requirements. Therefore, the question of what information asset and facility managers require of BIM to do their work still remains unanswered (Giel \& Issa, 2016).

Another challenge that asset managers encounter is insufficient, incomplete or incorrect data, which is influenced by the fact that contractors and suppliers only produce the data that they require (Brous, Overtoom, Herder, Versluis, \& Janssen, 2014). Similarly, Korpela et al. (2015) suggested that models used for design are not suitable for maintenance and that there is need for the careful specification of purpose and level of detail, including model contents. Furthermore, the optimal amount of information within a model for BIM-based processes is yet to be determined (Mayo \& Issa, 2014). As a result, data delivered for use in asset operations is lacking from the perspective of AM and FM. In most instances, handed-over data does not conform to the physical assets installed, and sometimes, updated asset data within the information models are not passed comprehensively to the user organisation (Lin et al., 2008). Hence, asset and facility managers end up with redundant and out-of-date documentation, which restricts the value that BIM can bring to an organisation.

A number of studies have attempted to investigate the development of operational information requirements with the aim of creating templates for asset owners (Ashworth, Tucker, \& Druhmann, 2016; Ashworth \& Tucker, 2017; Ashworth et al., 2017; Cavka et al., 2017). Ashworth et al. (2016) investigated the role of stakeholders in developing an EIR-BIM strategy and present a preliminary model for co-creation. However, the study fails to identify the key information requirements for asset owners. There have been efforts to develop a generic EIR document that sets out the information for delivery, including standards and processes as 
part of the project delivery process (Ashworth \& Tucker, 2017; Ashworth et al., 2017). Nevertheless, these studies present generic documents that do not identify operational information requirements in detail. Cavka et al. (2017) investigated two large owner organisations to better understand the process of developing operational information requirements. Although this study attempts to identify common information requirements, it ignores the impact of the asset owners' business sector on these requirements. Hence, a knowledge gap arises in identifying the critical operational information requirements for AM business processes.

\section{BIM-Based Information Requirements}

PAS1192-3 (BSI, 2014) suggested the need for information requirements and the development of an information model for the operations and use phase. Similarly, PAS1192-2 recommended a structured definition of the owner's requirements in building and infrastructure projects (BSI, 2013). Furthermore, PAS1192-3 presented the relationship between elements of BIM-based information management such as EIR, Organisational Information Requirements (OIR), Asset Information Requirements (AIR), Project Information Model (PIM) and Asset Information Model (AIM) (BSI, 2014). These are shown in Figure 1, whilst their connection to the asset's lifecycle is shown in Figure 2.

Insert Figure 1: Elements of BIM-based information management adapted from PAS1192-3 (BSI, 2014)

The process starts with the OIR, where the asset owner probes the business needs to identify the data and information required from the BIM-based processes in order to meet the needs of its AM system and other business functions (BSI, 2014). These are organisationallevel information requirements that are documented from different levels of the organisation. 
It is important for asset owners at this stage to develop business cases and to identify the anticipated business value of implementing BIM-based processes at every level of the organisation.

The next step is the development of the AIR, where the asset owner probes the OIR in relation to the organisational assets in order to identify the information requirements for BIMbased processes (BSI, 2014). These are asset-level requirements for executing AM tasks within owner-operator organisations. The AIR is a document that specifies the asset owners' information requirements for establishing an AIM (Patacas, Dawood, \& Kassem, 2016). It is necessary for asset owners to develop a deep understanding of their OIR and AIR in order to develop robust information requirements that will respond to business needs and derive BIM business value.

PAS1192-2 (BSI, 2013, p. 4) defines the EIR as a 'pre-tender document setting out the information to be delivered, and the standards and processes to be adopted by the supplier as part of the project delivery process'. The AIR forms the basis for the EIR, whilst the EIR is a significant tool for the client that aims to ensure that the right information is delivered in the right format and at the right time in the BIM process, from tendering to asset operations. An EIR should consist of: standard methods and procedures on information formats; a clear definition of information-related roles; an information delivery plan; recognition of the asset owner's existing Computer Maintenance Management Systems (CMMS); and a COBie demand matrix (BIFM, 2017).

The PIM represents the 'as-built' digital representation of the physical asset. This is developed progressively during the design and construction phases and handed over at the close out. The PIM is developed as specified by the EIR, and forms the basis for the AIM. Furthermore, it contains data which should be kept 'as-is' by the asset owner. An AIM is a graphical and non-graphical document, which consists of the data components of physical 
assets required to operate an asset and to provide organisational AM system support (BSI, 2014; Patacas et al., 2016). The AIM comprises the data defined in the EIR and comes from the PIM. Also, the information from the AIR is used to specify the AIM. In the information management process, the purpose of the AIM is to satisfy both the AIR and OIR, thereby ensuring that business value is realised by the asset owner.

Insert Figure 2: Elements of information management in relation to the asset's lifecycle

In the context of this study, operational information requirements refer to vital organisational requirements, which relate to AM business needs and processes, such that when utilised, it results in an immediate impact on BIM business value realisation for the asset owner. These operational requirements constitute some aspects of the requirement components contained in the OIR and AIR.

Despite the fact that PAS 1192-3 (BSI, 2014) presented a framework for the definition of elements contained in the information model, it does not cover the development of operational information requirements, OIR and AIR (Patacas et al., 2016). Also, asset managers are aware of the need to plan and request the information needed at the point of handover in relation to BIM-based processes, but they are ignorant of how to approach the problem (Ashworth, Tucker, \& Druhmann, 2019). Generally, there is a knowledge gap in the AEC industry concerning the approaches to develop operational information requirements and the subsequent monitoring and evaluation of data deliverables during the lifecycle of a facility in order to derive BIM business value.

\section{BIM-Based Information Exchange and Handover}

AEC industry standards, such as Information Delivery Manuals (IDM), Industry Foundation 
Classes (IFC), Model View Definitions (MVD), the buildingSMART Data Dictionary (bSDD) and the BIM Collaboration Format (BCF), have been developed for the creation, exchange and management of building information from the design and construction phases to the operations and use phase (Cavka et al., 2017). One of the challenges of this model-based information handover process is that asset owners do not have the tools, techniques, processes and protocols to effectively validate the completeness of the models (Cavka et al., 2018). Therefore, Patacas et al. (2016) presented a framework that conveys a structured definition of IDM, IFC and MVD. MVD is a subset of the IFC schema, which provides one or more exchange requirements. This structured framework combines the use of COBie and IFC in the development of an AIM to fulfill the AIR and OIR in order to deliver BIM business value. Similarly, Cavka et al. (2018) developed a three-level approach for a model-based compliance review to ensure that handedover information models are fit for purpose. Specifically, they address: (a) the model structure verification; (b) model content validation; and (c) the design compliance review. These processes rely on model queries based on a thorough investigation of the OIR and AIR in order to support a model-based handover, AM and FM business processes, and to enable BIM business value.

Furthermore, IFC and COBie are the two main open source schemas that fulfil the exchange requirements for BIM-based information exchange in AM (Eastman, Teicholz, Sacks, \& Liston, 2011; Patacas et al., 2016). The IFC schema is an open source data model that encodes the geometric and non-geometric information of objects in order to enable the effective exchange of model-based data (Patacas et al., 2016). It is an industry-developed product data model for the lifecycle design and management of facilities, which includes definitions of building elements in the form of objects including specific properties (Eastman et al., 2011). On the other hand, COBie, as a subset of IFC, is based on MVD (Patacas et al., 2016). It is a non-proprietary platform for data exchange in asset operations (East, 2014), and is simple to 
use because of its spreadsheet-like nature and structure in transferring data between software programmes (Kensek, 2015). COBie provides a structure for space and equipment information delivery to the asset owner by enabling the import of asset data from the design and construction phases into the AM and FM software (East, 2014). However, it omits some architectural elements that are relevant for asset refurbishment (Korpela et al., 2015). COBie is intended to encourage asset owners to articulate their operational information requirements concerning the data for inclusion in the information models. However, it does not support the asset owner to identify what to populate in order to realise value from the BIM-based processes (Mayo \& Issa, 2014). As a result, some asset owners are more disposed to linked and semantic data. Linked data refers to the processes of linking relationships between model-based and asset-centric information by semantically connecting assets rather than embedding data in objects (Boyes, Ellul, \& Irwin, 2017; buildingSMART, 2018). These linked relationships can be fixed, dynamic or inferred within the information models (buildingSMART, 2018).

In general, a review of literature has indicated the following: a lack of understanding of their informational requirements amongst asset owners; the need to define operational information requirements; a lack of process, protocols and standards to develop information requirements; and the need for practical evidence on how operational information requirements are developed.

\section{Methodology and Research Question}

\section{Research Question}

This study aimed to identify key operational information requirements in the context of BIM and how these relate to business needs and business value through a comparative study. The study sought to address the following research questions: 
- What are the organisational information requirements for AM processes, and how do these requirements relate to BIM?

- What are the common operational building information requirements for asset owners?

\section{Research Methods}

The research adopted case study and archival analysis research strategies to evaluate the operational information requirements of three asset owners. Yin (2003) suggested that the case study strategy is suitable for real-life contexts; thus, it was used to document the strategic operational building information requirements. Similarly, a multi-case comparative study allows for the investigation of similarities and differences between cases (Yin, 2003). This was used to compare and identify the most commonly defined operational information requirements amongst asset owners. Furthermore, archival analysis was utilised to analyse the operational information requirements in each case study (Saunders, Lewis, \& Thornhill, 2016).

The study was divided into two phases. The first phase comprised the literature review, where established strategies that document building information requirements were explored. The literature review sought to identify frameworks and methodologies developed by other studies in relation to the information requirement strategies, methods, tools and techniques. The second phase involved the multi-case comparative research, where operational information requirements were evaluated through a comparative analysis. This phase was divided into two stages, namely, the interview and document analysis. The research methodology is shown in Figure 3. 


\section{Case Study Selection}

This study utilised purposeful and snowballing sampling strategies to identify the cases and respondents. These types of sampling are suitable for studying real-world events, such as the development of templates for operational information requirements (Patton, 2002). Due to scarcity of templates for the development of information requirements for BIM-based processes in the AEC industry, snowballing was used to explore networks in order to identify participants (Saunders et al., 2016). Furthermore, the population of asset owners implementing BIM in the operations and use phase could not be determined, which made random sampling impracticable (Patton, 2002). The cases and participants were therefore selected based on the following criteria:

- Case Study 1: Granlund - This is a Finnish mechanical, electrical and plumbing (MEP) consultant that manages the operational data of over 1,000 clients globally through BIM. This company has developed a standard operational information requirement template for its clients.

- Case Study 2: University of California San Francisco-Health (UCSF) - This is a health sector owner-operator that owns and manages about 125 buildings of which 4 buildings and 1 hospital are managed through BIM-based processes. This asset owner has developed its standard operational information requirement template for internal data needs and operational maintenance activities.

- Case Study 3: Technical University Denmark (DTU) - This is an education sector client that owns and manages about 378 buildings through BIM-based processes. This asset owner has developed an operational information requirement template for internal business and data needs in asset operations. 
- All participants have advanced knowledge of BIM in asset operations.

- All participants are senior personnel responsible for the development of the operational information requirements template.

\section{Data Collection and Analysis}

This study adopted a qualitative approach to the data collection and mixed methods analysis (Saunders et al., 2016). This is because some aspects of the qualitative research data required systematic and standardised comparisons using quantitative descriptive statistics in order to understand the study data and graphically present the results. A qualitative approach allows for the probing of research questions with the aim of gathering information from the selected sample in order to identify the most commonly defined operational information requirements by asset owners.

Interviews and document analysis were utilised to collect and analyse the data. The benefit of using interviews is that it enabled the probing of issues regarding the operational and business-level information needs, thus, making it an effective investigative tool. During the course of the study, three interviews were conducted, with one for each case. The interviews helped to obtain qualitative accounts of the organisational approaches to developing operational information requirements. The study utilised the $\mathrm{NVivo}^{\mathrm{TM}}$ software to transcribe, code and analyse the interview data (Saunders et al., 2016). The coding technique enabled the easy analysis and cataloguing of the primary interview data (Boyatzis, 1998).

Furthermore, the study investigated internal documentation, such as information requirement templates, ICT specification standards, BIM implementation plans and BIM Execution Plans (BEP). Here, mixed methods were used to analyse these documents through a content analysis technique. This data analysis technique was used to evaluate differences and 
identify similarities between cases (Krippendorff, 2013). Content analysis enabled the qualitative multi-case comparative analysis (first-level analysis). Furthermore, a qualitative word frequency analysis was adopted in order to make inferences on the most commonly defined information requirements (second-level analysis) (Stemler, 2001). Additionally, quantitative descriptive statistics, such as bar charts and stacked bar charts, were used to comparatively analyse the distribution of information requirements across the requirement definition categories within the three selected case studies. These charts were generated using Microsoft Excel ${ }^{\mathrm{TM}}$ software (Walkenbach, 2015).

The operational informational requirements of the three case studies were analysed during a document analysis. First, data cleaning was carried out in order to detect and remove inconsistencies in order to improve the quality of the data (Saunders et al., 2016). This was significant because the operational information requirements, which included other documentation, were translated from Finnish to English (Granlund) and from Danish to English (DTU). Second, the operational informational requirements were read to understand the context of their application. The properties and property sets were then sorted into tables under the headings of business sector, general classification, standard description, general description, location description, installation description, product description, technical description, physical description and model reference. The sorting process was conducted iteratively until the information requirements were consistently grouped. Third, the first-level analysis was carried out to determine the differences. Fourth, the second-level analysis was conducted to identify similarities in the operational information requirements. Finally, due to the selection of the case studies, it was acknowledged that the results could be biased towards certain sectors of the AEC industry. 


\section{Results: Comparative Analysis}

\section{First Level Analysis: Differences}

This aspect of the analysis involves the analysis of differences within the general structure of the operational information requirements. These were analysed under classifications, such as business sector, strategy, BIM data perspective, general structure and object category. Table 1 shows the schematic analysis of the three cases.

Insert Table 1: Comparative analysis of operational information requirement schematic structure

\section{Sector}

From the analysis, the three cases represent different business perspectives, namely, MEP, Health and Education. Granlund is a MEP consultant that specialises in building services engineering. These requirements range from mechanical (heating, cooling, escalators, etc.), electric (power supply, lighting, control systems, etc.) and plumbing (pipes, drainage, fuel gas, etc.). UCSF, as a healthcare client, owns and operates healthcare buildings that contain facilities such as operating theatres, wards, outpatients, acute care inpatients, pharmaceutical compounding, laboratories, stem cell and accident and emergency units. These special requirements range from noise and vibration control in sensitive areas, such as hospital operation theatres. DTU, as an education sector client, has a wide range of different academic buildings consisting of offices, classrooms, lecture theatres, and laboratories. These all have different requirements in terms of: spatial planning, the flexible use of space, the control of vibrations, and acoustics. 
The above analysis indicates that the business sector of the asset owner has a clear relationship with the nature and type of information needs for BIM-based processes. As a result, the data requirements for Health and Education will be different.

\section{Strategy and BIM Data Perspective}

The development strategies differ across all three cases, including their BIM data perspectives; Granlund uses 'Co-development', UCSF uses 'Environment of Care', and DTU uses 'Data Ambassadors'. Furthermore, the BIM data perspectives also differ as Granlund uses IFC with COBie, UCSF uses native models with COBie, and DTU uses native models with linked data.

The data requirement development strategy of Granlund is guided by the Finnish Common BIM (COBIM) requirements, and uses the buildingSMART Finland property set tables. This is because their BIM data perspective is IFC. The operational information requirements were prepared through 'Co-development' with asset owners and other stakeholders in the AEC industry in Finland. However, Granlund highlighted that the operational information requirements (attached in Appendix B) are continuously developed. Thus, the data reviewed may not represent the final version because the organisation is still understanding phenomena related to BIM requirements in asset operations. Appendix B can be accessed through the following link:

https://drive.google.com/file/d/1aPgYevJHsWydz4sdIpJic2P6W871T0om/view?usp=sharing.

Secondly, UCSF adopts a unique strategy of specifying a higher level of detail and development on an identified 5\% asset requirement scope within their developed 'Environment of Care' requirement template. Although, UCSF uses great portions of the remaining $95 \%$ of asset requirements, they do not highly specify them. Instead, they allow the delivery of the requirements in accordance with the BEP and information delivery standards so as not to increase the cost of the whole process. These include mechanical, electrical, plumbing, water 
distribution, trade models, architectural models, CMMS, predictive, preventive and regulatory requirements that promote a safe, functional, and supportive environment within the organisation. The 5\% essentials are uniquely and prescriptively defined in the contractual documents, and are shown in Appendix C. UCSF's data perspective uses native building information models through Revit. Appendix $\mathrm{C}$ can be accessed using the following link: https://drive.google.com/file/d/1aPgYevJHsWydz4sdIpJic2P6W871T0om/view?usp=sharing.

Thirdly, DTU's strategy for data requirement development is channelled through the establishment of a BIM office that serves as 'Data Ambassadors' when structuring and communicating data within the organisation and across business units. This is because DTU's operational information requirements are generic and need to be specified further by the BIM office for every project. The operational information requirements were developed over a long period of time by interviewing departmental operational staff about each system and each component. Furthermore, whenever there is a request for data from the operational department, the BIM office acts as information brokers to deliver these kinds of data for asset operations. The requirements attached in Appendix D are specified in contractual documents. However, the BIM office is only responsible for developing the operational information requirements template and for translating what the operational department wants in the BIM context; therefore, the data content continues to be owned by the operational department. In other words, the BIM office is not responsible for what is in the template, but rather what parameters are available for which component. As such, DTU's data perspective uses native building information models through Revit and linked data. Appendix D can be accessed through the following link:

https://drive.google.com/file/d/1aPgYevJHsWydz4sdIpJic2P6W871T0om/view?usp=sharing.

In consideration of this analysis, the organisational strategy underpinning BIM implementation guides the operational information requirement template. Aspects, such as 
change management strategies, BIM-AM systems, systems architecture, network requirements and individual user requirements represent factors that influence the nature and content of operational information requirements. Therefore, the typical nature of any asset owner is markedly different and these organisational protocols make it difficult to maintain the same operational information requirements; this is particularly the case amongst organisations within the same sector. Furthermore, these aspects highlight that there are internal and external factors that influence business needs and operational information requirements for BIM-based AM processes that drive business value. Internal factors concern endogenous characteristics, such as organisational structure, strategy, technology, protocols and human resources. External factors refer to exogenous aspects, such as statutory requirements, environmental requirements and industry standards. Therefore, it is not possible to develop a 'one fit for all' operational information requirement template that will meet the needs of asset owners from all sectors.

\section{Schematic Structure}

The schematic structures are different and have diverse classifications for requirements across all cases. Although, Granlund and UCSF have a defined attribute definition sheet, DTU does not. The attribute definition sheet contains standards for data reporting, including data types (text, number, link, list, date, etc.), units, and detailed information on object property. Granlund has a group of headings with a matrix structure to identify the information requirements against the property sets, property, objects and software specifications. UCSF and DTU have a field entry system against the property sets and objects. Although, Granlund specifies text, numeric and other types of data requirement, there are no fields for entering such information on the requirement sheet as it is delivered through the IFC. UCSF and DTU have a field entry system with numeric, text and value fields that can be extracted through COBie or linked data. 
Nevertheless, considering the above, the schematic structure is an aspect that can be standardised by the AEC industry. Therefore, it is possible to develop a standard metarequirement template to provide a general structure through which asset owners can request information.

\section{Object Category}

The scope of object categories and individual objects of interest across all three cases are different. Here, Granlund as an MEP consultant have the smallest scope that only covers the mechanical, electrical and plumbing aspects. These are shown in Table 1 and Appendix B. On the other hand, UCSF focus on a wide range of object categories that are critical to their business needs as a health sector client. These are shown in Table 1 and Appendix C. DTU as an educational sector client have the widest range of requirements due to the differing natures of the building types within their asset operations. These are shown in Table 1 and Appendix D.

In view of the fact that the object categories of all three cases represent different systems or objects that are critical to the business needs of each client, it may not be possible to develop a rigid list of requirements that are applicable to all asset owners. Guidance templates and notes can be developed to highlight some categories that will help asset owners define their data requirements. Furthermore, developing a widely scoped requirements list that contains every piece of information will have its drawbacks, as there will be too many data fields to input. As such, personnel in the construction phase would find it too arduous to populate, and the delivery of this type of dataset would be an overkill for asset operations personnel, who will find it challenging to filter the necessary information sets in order to execute AM tasks. 


\section{Second Level Analysis: Similarities}

This analysis is based on the operational information requirements template of the three asset owners. Here, the requirements defined in the three cases are probed to identify similarities and the most common information requirements. This aspect of analysis consists of the property and attribute sets of the operational information requirements, such as (but not limited to) Object ID, Manufacturer, Model Type and LOD (Level of Detail/Development). This study utilises the following classifications to group information requirements; business sector, general classification, standard description, general description, location description, installation description, product description, technical description, physical description and model reference. Here, all the defined requirements are added to the property set classification headings above. Table 2 includes only information requirements that have been defined in at least two cases, and shows the information requirements including how many times they have been defined. The themes column consists of the properties and property sets, whilst the Granlund, UCSF and DTU columns indicate the defined requirements and specify the case. Moreover, the number column specifies the number of cases that have defined that requirement. The full extract of the operational information requirement template list is presented in Appendix A.

Insert Table 2: Summary of the requirements across all cases

From the analysis in Table 2 , although there are a total of 172 information requirement types (Appendix A), only $7(4 \%)$ requirements are common in all cases and $16(9 \%)$ are common in 2 cases. The remaining 149 information requirement types are mutually exclusive and identified in one case only. The analysed cases only share $23(13 \%)$ of the total defined requirements. Furthermore, the Product Description property set contains the most commonly 
defined requirements with 3 properties common in two and all cases respectively. This is followed by the General Classification property set with 4 and 2 properties common in two and all cases respectively. In addition, the Technical Description property set has the highest number of defined requirements with a total of 46. This is followed by the Product Description property set with a total of 28 requirement types. These results are shown in Figure 4.

Insert Figure 4: Frequently defined requirements in property sets across all cases

The Standard Description property set contains the most shared requirements across all cases compared to the other categories. Moreover, System Name (Common in 3), Link or Reference to Model (Common in 3), Storey or Level (Common in 2) and System Code (Common in 2) represent a total of 10 entries that are shared respectively out of a group sum of 13 entries. The least shared property sets are Location Description, Physical Description and Model Reference with no shared property. However, the purpose of this analysis is not to elicit every possible information requirement nor to make statistical inferences but rather to identify the commonly defined requirements within property sets and across all cases. Therefore, these findings indicate that the variation of operational information requirements across all cases result from differing business needs. It can be inferred that business needs determine operational information requirements, which enable the organisational BIM-based processes that drive BIM business value. Hence, the results highlight that there is a business value for the asset owner to request for the right information for AM tasks in the operations and use phase. Also, the findings suggest that operational information requirements are highly connected to business needs. 


\section{Discussion}

The research questions focused on evaluating operational information requirements and how they relate to BIM. The study answered the research questions by identifying the common BIM-based operational information requirements across three case studies, whilst the data analysis revealed that very few information requirements are shared across the three cases. This was due to the nature of the cases investigated, the business sector, information requirement development strategy, and BIM data perspective. Granlund as an MEP sector stakeholder is able to develop a detailed list due to the specialised nature of its operations. On the other hand, the UCSF perspective focuses on managing a whole facility. Here, the facilities department utilises a strategy of prioritising higher-level specifications for an agile 5\% that is critical to their in-house maintenance operations. Also, DTU have a similar perspective of managing the whole facility. They adopt a strategy of pulling data from the building models through linked data, which is facilitated by the BIM office. Hence, the differences emerge in terms of focus and detail amongst the list of operational information requirements for each case.

The main contribution of this study is the evaluation of critical owner requirements and the demonstration of how operational information requirement templates are structured as a guide to asset owners. The study evaluated aspects of operational information requirements, such as the business sector, strategy, BIM data perspective, schematic structure and object category, in relation to business needs. These factors ultimately lead to business value, which is the basis for adopting BIM-based processes. Furthermore, asset owners need to have a BIM strategy which aligns with their AM strategy in order to derive maximum value from the BIM process. Addressing the gap in knowledge by providing guidance to clients for the development of operational information requirements is another original contribution of this study. Finally, this study highlighted the link between the BIM and AM strategies, namely, the development 
of an operational information requirement template that focuses on business needs and whose execution generates business value for the asset owner.

\section{Conclusion}

The purpose of the study was to evaluate how asset owners articulate their information requirements for asset operations; it identified important categories and the most frequently requested asset information through a multi-case comparative study. The literature identified a knowledge gap in the understanding and development of operational information requirements by asset owners. The findings highlighted that there was the potential for business value for the client by defining information requirements that align with business needs.

The findings in this study led to five main conclusions. First, the study highlighted that there are internal and external factors that influence business needs which in turn impact on the operational information requirements for BIM-based processes. Second, it may not be possible to develop a rigid list of requirements that are applicable to all asset owners. Thus, only guidance templates and notes can be developed to highlight some categories that will help asset owners to define their data requirements. Third, very few requirements are shared across all cases; only $7(4 \%)$ requirements were common in all three cases and $16(9 \%)$ were common in 2 cases. The results showed that only $23(13 \%)$ of the total defined requirements were shared in 2 or more cases. Fourth, there are varying information requirements across all cases, which results from differing business needs. Finally, it is clear that operational information requirements are highly connected to business needs. Therefore, the business sector of the asset owner has a clear relationship with the nature and type of information needs for BIM-based processes. As such, asset owners need to understand their business needs in relation to their business requirements in order to derive value from BIM-based processes. 
In conclusion, future work could consider the development of a standard metarequirement template to guide asset owners by providing a general structure when requesting information from the design and construction phases. 


\section{References}

Ashworth, S., \& Tucker, M. (2017). BIFM employer's information requirements (EIR) template and guidance. Hertfordshire: British Institute of Facilities Management (BIFM).

Ashworth, S., Tucker, M., \& Druhmann, C. (2016). The role of FM in preparing a BIM strategy and employer's information requirements (EIR) to align with client asset management strategy. In Research papers for EuroFM's 15th research symposium at EFMC2016, 7-9 June (pp. 218228). Milan, Italy: Polyteknisk Forlag.

Ashworth, S., Tucker, M., \& Druhmann, C. (2017). Employer's information requirements (EIR): a BIM case study to meet client and facility manager needs. Madrid, Spain: 16th EuroFM Research Symposium: EFMC 2017, Vol. 16, 25-28th April.

Ashworth, S., Tucker, M., \& Druhmann, C. K. (2019). Critical success factors for facility management employer's information requirements (EIR) for BIM. Facilities, 37(1/2), 103-118.

Becerik-Gerber, B., Jazizadeh, F., Li, N., \& Calis, G. (2012). Application areas and data requirements for BIM enabled facilities management. Journal of construction engineering and management, 138(3), 431-442.

BIFM. (2017). Employer's information requirements (EIR): an overview of facilities management requirments. Hertfordshire: British Institute of Facilities Management (BIFM).

Boyatzis, R. (1998). Transforming qualitative information: thematic analysis and code development. Thousand Oaks, CA, USA: Sage Publications, Inc.

Boyes, G., Ellul, C., \& Irwin, D. (2017). Exploring BIM for operational integrated asset management a preliminary study utilising real-world infrastructure data. ISPRS Annals of Photogrammetry, Remote Sensing and Spatial Information Sciences. IV-4/W5: 12th 3D Geoinfo Conference 2017, 26-27 Octobe, (pp. 49-56). Melbourne, Australia.

Brous, P., Herder, P., \& Janssen, M. (2016). Governing asset management data infrastructures. Procedia Computer Science 9, 95(1), 303-310.

Brous, P., Overtoom, I., Herder, P., Versluis, A., \& Janssen, M. (2014). Data infrastructures for asset management viewed as complex adaptive systems. Procedia Computer Science, 36(1), 124 130.

BSI. (2013). Specification for information management for the capital/delivery phase of construction projects using building information modelling - PAS 1192-2:2013. London: The British Standards Institution 2013.

BSI. (2014). Specification for information management for the operational phase of assets using building information modelling - PAS 1192-3:2014. London: The British Standards Institution 2014.

buildingSMART. (2018). Infrastructure Asset Managers BIM Requirements: Version 1: Delivering the information 'Asset Managers' need and can trust using openBIM. buildingSMART International. Retrieved 03 23, 2019, from https://www.buildingsmart.org/wpcontent/uploads/2018/01/18-01-09-AM-TR1010.pdf 
Cavka, H. B., Staub-French, S., \& Poirier, E. A. (2017). Developing owner information requirements for BIM-enabled project delivery and asset management. Automation in Construction, 83, 169-183.

Cavka, H. B., Staub-French, S., \& Poirier, E. A. (2018). Levels of BIM compliance for model handover. Journal of Information Technology in Construction (ITcon), 23, 243-258.

Dawes, S. S. (2010). Stewardship and usefulness: policy principles for information-based transparency. Government Information Quarterly, 27(4), 377-383.

East, W. (2014). Construction-Operations Building Information Exchange (COBie). Retrieved 07 15, 2017, from http://www.wbdg.org/resources/cobie.php

Eastman, C., Teicholz, P., Sacks, R., \& Liston, K. (2011). BIM Handbook: a guide to building information modeling for owners, managers, designers, engineers and contractors (2nd ed.). Hoboken, New Jersey, USA: John Wiley \& Sons, Inc.

Giel, B., \& Issa, R. R. (2016). Framework for evaluating the BIM competencies of facility owners. Journal of Management in Engineering, 32(1).

Hoyer, W. D., Maclnnis, D. J., \& Pieters, R. (2013). Consumer behaviour (6th ed.). Ohio, Cincinati, USA: South-Western College Publishing.

Irani, Z. (2010). Investment evaluation within project management; an information systems perspective. The Journal of the Operational Research Society, 61(1), 917-928.

Jupp, J., \& Awad, R. (2017). A Change Management Perspective on BIM-FM Implementation. In M. Lamb (Ed.). 1, pp. 231-370. EPiC Series in Education Science: AUBEA 2017: Australasian Universities Building Education Association Conference 2017. Retrieved 12 12, 2017

Kensek, K. (2015). BIM guidelines inform facilities management databases: a case study over time. Buildings, 5, 899-916.

Korpela, J., Miettinen, R., Salmikivi, T., \& Ihalainen, J. (2015). The challenges and potentials of utilizing building information modelling in facility management: the case of the Center for Properties and Facilities of the University of Helsinki. Construction Management and Economics, 33, 3-17.

Krippendorff, K. (2013). Content analysis: an introduction to ist methodology (3rd ed.). Thousand Oaks, California, USA: Sage Publications, Inc.

Lin, S., Gao, J., \& Koronios, A. (2008). A data quality framework for engineering asset management. Australian Journal of Mechanical Engineering, 5(2), 209-219.

Love, P. E., Matthews, J., Simpson, I., Hill, A., \& Olatunji, O. A. (2014). A benefits realization management building information modeling framework for asset owners. Automation in Construction, 37(1), 1-10.

Mayo, G., \& Issa, R. R. (2014). Processes and standards for BIM closeout information deliverables for owners. Proceedings of 2014 International Conference on Computing in Civil and Building Engineering. June 23-25, 2014, (pp. 673-680). Orlando, Florida, USA. 
Parsanezhad, P., \& Dimyadi, J. (2014). Effective facility management and operations via a BIM-based integrated information system. Proceedings of CIB Facilities Management (CFM) 2014 Conference, 21-23 May, 2014. Copenhagen, Denmark.

Patacas, J., Dawood, N., \& Kassem, M. (2016). Supporting building owners and facility managers in the validation and visualisation of asset information models (AIM) through open standards and open technologies. Journal of Information Technology in Construction (ITcon), Special issue: CIB W78 2015 Special track on Compliance Checking, 21, 434-455. Retrieved 0402 , 2017, from http://www.itcon.org/2016/27

Patton, M. Q. (2002). Qualitative evaluation and research methods (3rd ed.). Thousand Oaks, California, USA: Sage Publications, Inc.

Saunders, M., Lewis, P., \& Thornhill, A. (2016). Research methods for business students (7th ed.). Harlow: Pearsons.

Stemler, S. (2001). An overview of content analysis. Practical Assessment, Research and Evaluation, $7(17)$.

Walkenbach, J. (2015). Microsoft ${ }^{\circledast x c e} \mathrm{I}^{\circledast} 2016$ - Bible. Indianapolis: John Wiley \& Sons.

Yin, R. K. (2003). Case study research: design and methods (3rd ed.). Thousand Oaks, CA, USA: Sage Publications, Inc. 